\title{
ON AUTHOR, COPYRIGHT AND ORIGINALITY: DOES THE UNIFIED EU ORIGINALITY STANDARD CORRESPOND TO THE DIGITAL REALITY IN WIKIPEDIA?
}

by

AURELIJA LUKOŠEVIČIENË ${ }^{*}$

This article is contributing to the future of copyright law debate by exploring the recently harmonised originality standard in the EU copyright law and its suitability to a creative sharing community of Wikipedia. It shows that the "free creative choices" and "author's personal" touch criteria established by the CJEU might be unsuitable not only because of practical concerns, but also because the understanding of "author" they are based on does not match the understanding possessed by Wikipedia community. The concepts of author (or rather author and Wikipedian) are compared through three key elements: author's relationship with work, author's relationship with others and presumptions about author's personality and creative process.

\section{KEY WORDS}

Copyright Law, Concept of Author, Originality, Wikipedia

\section{INTRODUCTION}

One of the seemingly never-ending debates in the context of copyright law in the recent years is its further development and adaptation to the digital technologies and the Internet. This debate is especially complicated not only because the potentials of current technology makes it harder (or even impossible) to control copying and dissemination of copyrighted works, but also because in the digital environment the traditional limits between 
the three central actors, namely those of authors, users, and intermediaries, are blurring and shifting and the content of these concepts is changing.

One of the biggest tensions, which this article is also set to address, is the one between authors and users that is visible especially when looking into phenomena like User Generated Content (UGC). Here, even those who are traditionally considered as "users" are producing their own creative works, and those who could be traditionally called "authors" engage in non-traditional (even if only because of their scope) creative practices and partly or completely refuse the protection of copyright law. Moreover, the distinction between authors and users in the Web 2.0 environment is often sensitive to ideological context and even employed to diminish the status and protection of on-line creators. ${ }^{1}$

There is a body of research trying to place the UGC creators somewhere in the author/user scale and calling them prosumers ${ }^{2}$, mini creators $^{3}$, or similar. Attempts have also been made to understand these actors more in terms of "authors" and explore what makes them different from the classic (often called "romantic") model of authorship and what makes them oppose the traditional copyright monopoly. ${ }^{4}$ This article will concentrate on the latter approach and will use the example of Wikipedia, analysing it as a community of "authors". Taking as its legal background the EU copyright law and one of its cornerstones - the recently unified standard of originality - this article will compare the Wikipedians to the authors of the EU copyright law and will elaborate what originality could mean in the cases of digital communities like Wikipedia.

Erickson, K. (2014) User illusion: ideological construction of 'user-generated content' in the EC consultation on copyright. Internet Policy Review, 3 (4).

2 Bruns, A. (2006) Blogs, Wikipedia, Second Life and Beyond. From Production to Produsage, New York: Peter Lang.

3 Kawashima, N. (2010) The rise of 'user creativity' - Web 2.0 and a new challenge for copyright law and cultural policy. International Journal of Cultural Policy, 16 (3).

4 See Dusollier, S. (2003) Open Source and Copyleft: Authorship Reconsidered. Columbia Journal of Law $\mathcal{E}$ the Arts, 26 (3); Zhu, C. W. (2014) A regime of droit moral detached from software copyright? - the undeath of the 'author' in free and open source software licensing. International Journal of Law and Information Technology, 22 (4); Halbert, D. (2014) The State of Copyright: the Complex Relationships of Cultural Creation in a Globalised World, New York: Routledge, pp. 181-200. 


\section{AUTHOR AND ORIGINALITY AS HARMONISED EU COPYRIGHT STANDARD}

There is little doubt that originality is one of the main concepts in copyright law. It is the criterion which ultimately determines if a creative work expressed in a tangible form is worthy of copyright protection. Differently from literary and every-day usage of the term, in the context of copyright law, originality is more related to "origination", not uniqueness. ${ }^{5}$ On the other hand, in addition to requirement of origination, i.e. requirement for a work to "originate" from the author directly and not to be copied, both the continental and the common law copyright traditions also ask for something more, namely, creativity, skill, effort or judgement which were exercised in the process of origination. ${ }^{6}$ In effect, the process which the author went through to create a work, and his or her ${ }^{7}$ personal qualities and skills become part of investigation for originality assessment. Accordingly, the way the "author", his creative process and his role in the society are seen becomes one of the key determinants for what is protected by copyright law. This can be also observed in connection to the recently harmonized originality standard in the EU. ${ }^{8}$

This harmonisation of the standard of originality started in 2009 with the CJEU Infopaq case and then continued with BSA, Football Association Premier League, Painer, and finally, Football Dataco in 2012. In its decisions, the Court not only established the 'free creative choices' and, in Painer, 'personal touch' as the cornerstones for awarding copyright protection to a creative work of any kind, but also used arguments allowing

5 Van Gompel, S. (2014). Creativity, autonomy and personal touch. A critical appraisal of the CJEU's originality test for copyright. In: van Eechoud, M. (ed.) The Work of Authorship. Amsterdam University Press.

6 See, for instance, Torremans, P. (2007) Legal Issues Pertaining to the restoration and re-constitution of manuscripts, sheet music, paintings and films for marketing purposes. In: Torremans, P. (ed.) Copyright Law. A Handbook for Contemporary Research. Cheltenham: Edward Elgar, p. 31, for description of "two requirements" of the UK originality standard or Quaedvlieg, A. (2014) The tripod of originality and the concept of work in Dutch and European copyright. GRUR Int., 63 (12), for a model of three elements of originality for analysing Dutch and EU standards. See also Peifer, K.-N. (2014) "Individualität" or Originality? Core concepts in German copyright law. GRUR Int., 63 (12).

7 From here on in the rest of the article the default pronouns of "she" and "hers" will be used when refering to "author". This is mainly in order to, together with the arguments in the text itself, challenge the readers own concept of author which is often expressed through pronouns indicating male gender.

8 Most now agree that the standard of originality is now de facto harmonized in the EU copyright law. See Rosati, E. (2013) Originality in EU Copyright. Full Harmonization through Case Law, Cheltenham: Edward Elgar. 
certain insights on the type of author the EU copyright law is being set out to protect.

In the landmark Infopaq", the court set out to give an autonomous interpretation for "reproduction" and "reproduction in part" which in turn led it to consider the notion of "work" in the context of "InfoSoc" Directive. The CJEU concluded that it means

"subject matter which is original in the sense that it is its author's own intellectual creation" ${ }^{10}$

and stressed that when it comes to a news article, its originality is achieved through the form and the manner of presentation and author's linguistic expression. ${ }^{11}$ All of these original elements are to be protected by copyright law and accordingly, any part of the work which contains these elements has to be protected as well. The CJEU concluded that where protection was sought for text extracts from news articles (parts of original text), it was through choice, sequence, and combination of words that intellectual creation could be achieved. ${ }^{12}$

In $B S A^{13}$, the CJEU faced a question of whether a graphic user interface can be protected by copyright as an expression of the software itself and ruled that the Computer Programs Directive gives protection to certain parts of software but not the user interface. ${ }^{14}$ However, graphic user interface can be protected in its own right if it is an original work, following the Infopaq criteria, concluded the Court. In this case,

"the specific arrangement or configuration of all the components which form part of the graphic user interface"15

9 Infopaq International A/S v. Danske Dagblades Forening (2009) Case no. C-5/08. Court of Justice of the European Union, ECR I-06569.

10 Infopaq International A/S v. Danske Dagblades Forening (2009) Case no. C-5/08. Court of Justice of the European Union, ECR I-06569, para. 37.

11 Infopaq International A/S v. Danske Dagblades Forening (2009) Case no. C-5/08. Court of Justice of the European Union, ECR I-06569, para. 44.

${ }_{12}$ Infopaq International A/S v. Danske Dagblades Forening (2009) Case no. C-5/08. Court of Justice of the European Union, ECR I-06569, para. 45.

13 Bezpečnostní softwarová asociace - Svaz softwarové ochrany v. Ministerstvo kultury (2010) Case no. C-393/09. Court of Justice of the European Union, ECR I-13971.

${ }^{14}$ Bezpečnostní softwarová asociace - Svaz softwarové ochrany v. Ministerstvo kultury (2010) Case no. C-393/09. Court of Justice of the European Union, ECR I-13971, para. 41.

15 Bezpečnostní softwarová asociace - Svaz softwarové ochrany v. Ministerstvo kultury (2010) Case no. C-393/09. Court of Justice of the European Union, ECR I-13971. 
were named as possibly original, but not those, which are determined by their technical function only. ${ }^{16}$ In other words, merely following the requirements of technical function, an author cannot achieve "intellectual creation", since his creativity is not possible to express in an original manner, concluded the CJEU. ${ }^{17}$

The next decision to come in 2011 was Football Association Premier League $^{18}$ where the CJEU had to deal with, among other things, a question of whether Premier League matches could be copyrighted in their own right. The Court held that a football game couldn't be a work in copyright sense, because it lacks originality. It concluded that sporting events are subject to rules and leave

"no room for creative freedom for the purposes of copyright"19.

In the end of the same year, the Court also decided on Painer ${ }^{20}$ which involved unauthorised actions towards a school portrait picture of a child. The Court, among other things, had to rule on whether the picture in question could be protected by copyright at all since the degree of formative freedom when creating such portrait picture is rather restricted. ${ }^{21}$ Here the CJEU once again explained ability to make free and creative choices as the key condition for originality ${ }^{22}$ and regarding portrait photographs, it outlined that these can be exercised through choice of background, subject's pose, lighting, framing of the photo, angle

16 Bezpečnostní softwarová asociace - Svaz softwarové ochrany v. Ministerstvo kultury (2010) Case no. C-393/09. Court of Justice of the European Union, ECR I-13971, paras. 48-49.

17 Bezpečnostní softwarová asociace - Svaz softwarové ochrany v. Ministerstvo kultury (2010) Case no. C-393/09. Court of Justice of the European Union, ECR I-13971, para. 50.

18 Football Association Premier League Ltd, NetMed Hellas SA, Multichoice Hellas SA v. QC Leisure, David Richardson, AV Station plc, Malcolm Chamberlain, Michael Madden, SR Leisure Ltd, Philip George Charles Houghton, Derek Owen, and Karen Murphy v. Media Protection Services Ltd (2011) Joined cases nos. C-403/08 and C-429/08. Court of Justice of the European Union, ECR I-10909.

19 Football Association Premier League Ltd, NetMed Hellas SA, Multichoice Hellas SA v. QC Leisure, David Richardson, AV Station plc, Malcolm Chamberlain, Michael Madden, SR Leisure Ltd, Philip George Charles Houghton, Derek Owen, and Karen Murphy v. Media Protection Services Ltd (2011) Joined cases nos. C-403/08 and C-429/08. Court of Justice of the European Union, ECR I-10909, para. 98.

20 Eva Maria Painer v. Standard Verlags GmbH and others (2011) [unreported] Case no. C-145/10. Court of Justice of the European Union, 7 March.

${ }^{21}$ Eva Maria Painer v. Standard Verlags GmbH and others (2011) [unreported] Case no. C-145/10. Court of Justice of the European Union, 7 March, para. 85.

22 Eva Maria Painer v. Standard Verlags GmbH and others (2011) [unreported] Case no. C-145/10. Court of Justice of the European Union, 7 March, para. 89. 
of the view, atmosphere created and developing techniques. ${ }^{23}$ Quoting the court:

"By making those various choices, the author of a portrait photograph can stamp the work created with his 'personal touch'."24

This was enough to recognise the picture original, even though the actual choices exercised by the author in this case did not make the picture distinguishable from most other school portrait pictures.

Finally, in Football Dataco ${ }^{25}$, the Court dealt with a question of originality of fixture list of matches to be played in English and Scottish football leagues in a year. Here, the CJEU explicitly dismissed the traditional common law "skill and labour" standard stating that even significant labour and skill are not enough to proclaim a database original. ${ }^{26}$ Neither "adding important significance" to the data would be enough for this purpose either. ${ }^{27}$ The Court, referring, to all the previous originality cases, reiterated that originality is about making "free and creative choices" and stamping "personal touch" on the final work and no amount of labour or investment can replace that. $^{28}$

Turning to the presumptions and expectations for the "author" one can read in and between the lines of these decisions, they all speak about creativity as the basis of copyright protection. This, however, is not any kind of creativity, but original creativity, or rather creativity expressed in an original manner. It is important to repeat here that "original" has nothing to do with aesthetics, uniqueness or any other merit or quality this is a specific legal construction hiding behind the same word as used

23 Eva Maria Painer v. Standard Verlags GmbH and others (2011) [unreported] Case no. C-145/10. Court of Justice of the European Union, 7 March, para. 91.

${ }^{24}$ Eva Maria Painer v. Standard Verlags GmbH and others (2011) [unreported] Case no. C-145/10. Court of Justice of the European Union, 7 March, para. 92.

25 Football Dataco Ltd, Football Association Premier League Ltd, Football League Ltd, Scottish Premier League Ltd, Scottish Football League, PA Sport UK Ltd v. Yahoo! UK Ltd, Stan James (Abingdon) Ltd, Stan James plc, Enetpulse ApS (2012) [unreported] Case no. C-604/10. Court of Justice of the European Union, 1 March.

${ }^{26}$ Football Dataco Ltd, Football Association Premier League Ltd, Football League Ltd, Scottish Premier League Ltd, Scottish Football League, PA Sport UK Ltd v. Yahoo! UK Ltd, Stan James (Abingdon) Ltd, Stan James plc, Enetpulse ApS (2012) [unreported] Case no. C-604/10. Court of Justice

27 Ibid.

${ }^{28}$ Football Dataco Ltd, Football Association Premier League Ltd, Football League Ltd, Scottish Premier League Ltd, Scottish Football League, PA Sport UK Ltd v. Yahoo! UK Ltd, Stan James (Abingdon) Ltd, Stan James plc, Enetpulse ApS (2012) [unreported] Case no. C-604/10. Court of Justice of the European Union, 1 March, para. 38. 
in non-legal fields. ${ }^{29}$ Thus, originality in the EU copyright law as interpreted by the CJEU means creativity expressed through intellectual process of free creative choices, which in its turn means that these choices cannot be constricted by technical requirements or rules (like in BSA or Football Association Premier League). It remains to be seen to what extent different kinds of other restrictions on creative choices present in normal creative process (such as constrains of methods, materials, intended audience, contractual relationships, etc.) $)^{30}$ could be considered as falling outside originality in the future interpretations of the standard. In any case, the main presumption about the creativity of the author here is rather clear - there has to be an unrestricted space where intellectual ${ }^{31}$ choices and decisions can be made by the author. The actual choices exercised by the creator and the final result are not that relevant, as the Court clearly indicates in Painer, where even a barely distinctive portrait picture is proclaimed original since there was significant creative freedom the author could have exploited. Therefore, the most valuable and protected is author's power and the ability to shape the surrounding world into a creative work. ${ }^{32}$ There being no additional requirements for quality and rather weak emphasis on the final work, this power is presumably something that every human being possesses and everyone can be an "author".

On the other hand, even though the emphasis is clearly on the possibility for free creative choices, the CJEU in Painer also introduced something that at least to some extent speaks about the relationship of the author with the final work - the "personal touch" requirement. In the line of the above analysis, however, the Painer decision presented it more like a consequence of free creative choices, than a separate criterion to be investigated when determining originality. ${ }^{33}$ In some way, the idea that anyone exercising creativity is bound to leave personal touch on a work introduces the idea

29 Lavik, E., van Gompel, S. (2013) On the Prospects of Raising the Originality Requirement in Copyright Law: Perspectives from the Humanities. Journal, Copyright Society of the U.S.A., 60 (3), p. 387, and van Gompel, S., Lavik, E. (2013). Quality, Merit, Aesthetics and Purpose: An Inquiry Into EU Copyright Law's Eschewal of other Criteria than Originality. Revue Internationale du Droit d'Auteur (RIDA), 236.

30 See van Gompel, S. (2014) Creativity, autonomy and personal touch. A critical appraisal of the CJEU's originality test for copyright. In: van Eechoud, M. (ed.) The Work of Authorship. Amsterdam: Amsterdam University Press.

31 Even though it is quite curious to call "intellectual" something that is quite the opposite of making decisions on the most effective way to accomplish a task.

32 Something that is, for instance, an interpretation of the EU originality standards that the Dutch courts seem to have, see van Gompel, S. 2014. Creativity, autonomy and personal touch. A critical appraisal of the CJEU's originality test for copyright. In: van Eechoud, M. (ed.) The Work of Authorship. Amsterdam: Amsterdam University Press. 
that everyone is unique, which together with the previously identified presumption of "free" individual choices lands the current standard of originality somewhere close to the "romantic author" figure. ${ }^{34}$ On the other hand, the seeming presumption that everyone is unique is quite different from the more elitist "creativity of the few" understanding that the model of the romantic author is usually accused of. Still, it remains to be seen if this "personal touch" criterion will not be used to qualify the very low and egalitarian "space of free creative choices" standard with assessment of the work and its "personal" (i.e. non-generic) nature after all. This is how this standard has always been understood in, for instance, in the French copyright law. ${ }^{35}$

Such construction of originality also gives a glimpse on how the Court envisions the relationship of the author to the rest of the society - this is the author and her free creativity that is in the centre, the final work as such does not necessarily have to be of any use to the rest of the world. The preamble of "InfoSoc" directive states that there is a need of high level of protection in order to secure reward for the author ${ }^{36}$ - something that is later repeated in Infopaq and other cases. This reward, however, is there to "ensure maintenance and development of creativity" (recital 9), finance authors' works (recital 10), and "safeguard the independence and dignity of artistic creators" (recital 11). The "consumers" and "public at large" are also interest groups mentioned in the "InfoSoc" preamble", but only once explicitly (and several more times when refereeing to "public interest"), and therefore seem to have a rather secondary importance. As can be expected, this is a standard and understanding rather different from "limited monopoly for the benefit of the public" perspective often found

33 Eva Maria Painer v. Standard Verlags GmbH and others (2011) [unreported] Case no. C-145/10. Court of Justice of the European Union, 7 March, para. 92.

34 See, for instance Jaszi, P. (1994) On the Author effect: Contemporary Copyright and Collective Creativity. In: Woodmansee, M., Jaszi, P. (eds.) The Construction of Authorship. Textual Appropriation in Law and Literature. Durham: Duke University Press. For detailed analysis of the scholarship on "romantic author" see Lavik, E. (2014) Romantic authorship in copyright law and the uses of esthetics. In: van Eechoud, M. (ed.) The Work of Authorship. Amsterdam: Amsterdam University Press.

35 Rosati, E. (2013) Originality in EU Copyright. Full Harmonization through Case Law. Cheltenham: Edward Elgar, p. 71.

36 Directive 2001/29/EC of the European Parliament and of the Council of 22 May 2001 on the Harmonisation of Certain Aspects of Copyright and Related Rights in the Information Society, Official Journal of European Union (L 167/10) 22 June, Recitals 9-11.

37 Directive 2001/29/EC of the European Parliament and of the Council of 22 May 2001 on the Harmonisation of Certain Aspects of Copyright and Related Rights in the Information Society, Official Journal of European Union (L 167/10) 22 June, Recital 9. 
in Anglo-American copyright justifications. ${ }^{38}$ Hence, the usefulness for the rest of the society is understood through maintenance of "creativity", authors' continuous work and their protection, but not in terms of economic or other type of efficiency. Accordingly, in Football Dataco the CJEU explicitly rejected the "skill and effort" or the "sweat of the brow" doctrine of originality - presumably this is not something that the EU copyright and the Court consider as sufficiently important to protect. The author is not someone who necessarily works hard - even something as 11 words can be original in the standard of Infopaq. In addition, as also explicitly confirmed in Football Dataco, even if the final work has utility to the public, even if "important significance" was added to the raw data by the aspiring author, she will not be considered "author" by the EU copyright law, unless the process of "free creative choices" can be confirmed.

Consequently, one sees a complex picture of author that the analysis of the CJEU cases is drawing in the context of originality. On the other hand, three main aspects, namely, 1) author's relationship with the work, 2) author's relationship with society, and 3) presumptions about author's creative process including her personal qualities can be seen as three main topics the court elaborated on in the reviewed decisions. As presented in the beginning of the text, the article will now turn to Wikipedia to compare the presumptions and requirements for Wikipedians and to see how Wikipedia then fits in into the picture of "authors" and "creativity" that the CJEU is drawing.

\section{ORIGINALITY IN THE DIGITAL CONTEXT, THE CASE OF WIKIPEDIA}

\subsection{THE PHENOMENON OF WIKIPEDIA}

Wikipedia, as presented in the website of the project itself, is

"a multilingual, web-based, free-content encyclopedia project supported by the Wikimedia Foundation and based on a model of openly editable content ${ }^{\prime \prime 39}$.

${ }^{38}$ See, for example, Samuelson, P. (2003-2004) Should Economics Play a Role in Copyright Law and Policy? University of Ottawa Law \& Technology Journal, 1 (2).

${ }^{39}$ (2017) Wikipedia: About. [online] Available from: https://en.wikipedia.org/wiki/Wikipedia: About [Accessed 10 February 2017]. 
In other words, this is a project based on voluntary collaborative contributions aimed at creating a free encyclopaedia which can be edited by anyone accessing it (anonymously or not, depending on the choice of the editor). The official statistics shows that as for August 2016 there were over 29 million registered editors, ${ }^{40}$ around 13,5 million edits ${ }^{41}$ were made and there were more than 10000 of registered contributors who made more than 100 edits that month. ${ }^{42}$ In total, it makes for an enormous group of people working on a common goal and impressive amounts of hours invested by contributors, especially the very active ones. ${ }^{43}$ The main normative framework connecting all the contributors of the project are the "Five Pillars" ${ }^{44}$ which reflect the most fundamental principles all other Wikipedia guidelines and policies derive from. These are the rules that are valid globally and are to be respected in all project's language communities. Aside from that, each of them has a degree of freedom to self-organise and even though the rules and principles are often similar among them, there are certain differences too, and this is why the research that will follow next will be in relation to English language Wikipedia only.

As explained in the introductory part, this article will consider "Wikipedian" not from the perspective of user, prosumer or similar, but, will try to see her as an "author" and compare her with the "author" formulated in the CJEU judgements above. In this respect, it is interesting to observe that people creating text on Wikipedia are in the community itself called many different things: authors ${ }^{45}$, Wikipedians ${ }^{46}$, contributors ${ }^{47}$, and even users $^{48}$, without much controversy or, seemingly, deeper reflection. This

${ }^{40}$ (2017) Wikipedia: Statistics. [online] Available from: https://en.wikipedia.org/wiki/Wikipedia: Statistics [Accessed 10 February 2017].

${ }^{41}$ (2017) Wikipedia Statistics. [online] Available from: https://stats.wikimedia.org/EN/Tables DatabaseEdits.htm [Accessed 10 February 2017].

42 (2017) Wikipedia Statistics, [online] Available from: https://stats.wikimedia.org/EN/Tables WikipediansEditsGt100.htm [Accessed 10 February 2017].

${ }^{43}$ Sundin, O. (2010) Janitors of Knowledge: constructing knowledge in the everyday life of Wikipedia editors. Journal of Documentation, 67 (5).

${ }^{44}$ (2017) Wikipedia: Five Pillars. [online] Available from: https://en.wikipedia.org/wiki/ Wikipedia:Five_pillars [Accessed 10 February 2017].

45 (2017) Wikipedia: Authors of Wikipedia. [online] Available from: https://en.wikipedia.org/wiki/ Wikipedia:Authors_of_Wikipedia [Accessed 10 February 2017].

${ }^{46}$ (2017) Wikipedia: Wikipedians. [online] Available from: https://en.wikipedia.org/wiki/ Wikipedia:Wikipedians [Accessed 10 February 2017].

${ }^{47}$ (2017) Wikipedia: Who writes Wikipedia?. [online] Available from: https://en.wikipedia.org/ wiki/Wikipedia:Who_writes_Wikipedia\%3F [Accessed 10 February 2017].

48 See, for example (2017) Wikipedia: Wikipedians. [online] Available from: https://en.wikipedia. org/wiki/Wikipedia:Wikipedians [Accessed 10 February 2017]. 
might show that there simply is no clear consensus in the community on how the person contributing to it should be called, but perhaps also that such joint name is not needed - there could be other methods to distinguish who is in the community and who is outside it. Academic studies, on the other hand, seem to be using "author" more often to describe Wikipedia contributors, ${ }^{49}$ but other names like editors, contributors, Wikipedians, participants, etc. ${ }^{50}$ On the other hand, in academic and empirical studies Wikipedia is also often called a "UGC phenomenon", UGC site or something along these lines ${ }^{51}$ and the contributors are called simply users ${ }^{52}$. In this article, for instance, the choice was made to use "Wikipedian" as the predominant concept to describe Wikipedia contributors in order to draw attention to the Wikipedian as an autonomous phenomenon distinct from and possible to compare with the legal "author".

The first material sign that Wikipedian might mean something slightly different from "author" in the EU copyright law and that even the standard of originality might differ between these two contexts are the rules of attribution of Wikipedia ${ }^{53}$. These rules put forward that the first choice for proper attribution is to provide an URL to the relevant Wikipedia site but in case this is impossible, there is also an option of listing all authors of a specific article (presumably the Wikipedians provided in the history/log of edits). The preference for URL referencing is understandable, because of the sheer number of contributors one would need to list and also because the log contains all possible edits, including vandalism, bulk deletions, things like, for instance, inclusion of one comma, etc. Taking this into

49 For instance Pentzold, C. (2010) Imagining the Wikipedia community: What do Wikipedia authors mean when they write about their 'community'. New Media E Society, 13 (5); or Halatchliyski, I., Moskaliuk, J., Joachim, K., Cress, U. (2014) Explaining authors' contribution to pivotal artefacts during mass collaboration in the Wikipedia's knowledge base. Computer Supported Cooperative Learning, 9 (1), pp. 97-115.

50 Examples of studies using different notions: Lai, C.-Y., Yang, H.-L. (2014) The reasons why people continue editing Wikipedia content - task value confirmation perspective. Behaviour $\mathcal{E}$ Information Technology, 33 (12); also Sundin, O. (2010) Janitors of Knowledge: constructing knowledge in the everyday life of Wikipedia editors. Journal of Documentation, 67 (5); and others.

51 See, for instance, Nov, O. (2007) What Motivates Wikipedians. Communications of the ACM, 50 (11); Yang, H.-L., Lai, C.-Y. (2010) Motivations of Wikipedia Content Contributors. Computers in Human Behavior, 26 (6), pp. 1377-1383.

52 For instance in $\mathrm{Xu}, \mathrm{B} ., \mathrm{Li}, \mathrm{D}$. (2015) An empirical study of the motivations for content contribution and community participation in Wikipedia. Information $\mathcal{E}$ Management, 52 (3).

53 Can be found in several sites containing community rules including: (2017) Wikipedia: Reusing Wikipedia Content. [online] Available from: https://en.wikipedia.org/wiki/Wikipedia: Reusing_Wikipedia_content [Accessed 10 February 2017], or (2017) Wikipedia: Copyrights. [online] Available from: https://en.wikipedia.org/wiki/Wikipedia:Copyrights [Accessed 10 February 2017], under "Re-users' rights and obligations". 
consideration, the rule of attribution allows omitting minor and irrelevant contributions - something that might seem similar to originality threshold in copyright law. However, there are also clear differences from the copyright law, giving a hint on the nature of Wikipedian "originality" already. First of all, the rule explicitly excludes irrelevant contributions (with no reference to their extent) - so those that, for instance, did not follow the topic of the article. Moreover, it does not exclude major but merely technical contributions (like, finding sources, adding references, adding tags, large scale formatting and other technical tasks that form a big part of a work of Wikipedian ${ }^{54}$ ) nor any changes of content even as small as one word. $^{55}$ As a contrast, the CJEU in the cases above provided that creative activities restrained by technical requirements and rules do not qualify as original and so merely making the text fit the format requirements of Wikipedia would normally not be an act of authorship in the EU copyright law. Lastly, the rule, arguably, does not exclude non-minor contributions which might be now almost or completely re-written by someone else and therefore not present in the article anymoresomething that would only fall under copyright protection only if joint authorship criteria would be satisfied. ${ }^{56}$

All of this gives the impression that "Wikipedian" is a more inclusive concept than copyright "author", at least when it comes to one aspect of authorship, namely, attribution. The article will now follow to examine and compare other aspects of authorship already identified in the CJEU judgements: 1) author's relationship with the work, 2) author's relationship with society, and 3) presumptions about author's creative process including her personal qualities.

\subsection{WIKIPEDIAN'S RELATIONSHIP WITH WORK}

The question to answer when looking at this aspect is "what kind of relationship with the work is expected and valued in Wikipedia community?".

54 Sundin, O. (2010) Janitors of Knowledge: constructing knowledge in the everyday life of Wikipedia editors. Journal of Documentation, 67 (5).

55 More about what is considered minor and what is a major edit can be found at (2017) Help: Minor edit. [online] Available from: https://en.wikipedia.org/wiki/Help:Minor_edit [Accessed 10 February 2017].

56 Description of the problems of establishing authorship in the context of online collaborative projects like Wikipedia can be found in Phillips, J. (2009) Authorship, ownership, wikiship: copyright in the $21^{\text {st }}$ century. In: Derclaye, E. (ed.) Research Handbook on the Future of EU Copyright. Cheltenham: Edward Elgar. 
In the context of the EU copyright law, or rather the CJEU decisions on originality, author's relationship with her work was described in the form of "personal touch" that the author gives to it and the general emphasis on author's independence, dignity and possibilities for her to exercise her creativity through the protection of law.

Looking into Wikipedia and the relationship individual Wikipedians have to their work, there have been a great number of studies carried out on the motivations of contribution to this project during the time of its existence. $^{57}$ As could be expected, they predominantly found intrinsic motivations ${ }^{58}$, as fun (enjoyment/pleasure), ideology (of openness), values (related to altruistic and humanitarian concerns for others) being key for contribution. Extrinsic motivations such as reputation, reciprocity and self-development (improvement of skills and knowledge) were among those positively correlating with sharing behaviour, but usually to a lesser extent than the intrinsic ones. In other words, most authors of Wikipedia contribute because it feels good to do it, because they consider that they are helping society by making information freely available and easily accessible or because they have strong ideological conviction on that knowledge needs to be free. The motivation that comes with the presence of community itself, like recognition, reciprocity, and wish to improve one's knowledge about a certain subject also play an important role, but perhaps not as important as in, for instance, Open Source communities. ${ }^{59}$ Creative autonomy or rewards in order to be able to continue creative work seemingly do not have significant presence in the relationship Wikipedians have with their

57 See, for instance, $\mathrm{Xu}, \mathrm{B}$., Li, D. (2015) An empirical study of the motivations for content contribution and community participation in Wikipedia. Information \& Management, 52 (3), Yang, H.-L., Lai, C.-Y. (2010) Motivations of Wikipedia Content Contributors. Computers in Human Behavior, 26 (6), pp. 1377-1383; Lai, C.-Y., Yang, H.-L. (2014) The reasons why people continue editing Wikipedia content - task value confirmation perspective. Behaviour \& Information Technology, 33 (12); Nov, O. (2007) What Motivates Wikipedians. Communications of the ACM, 50 (11); Yang, H.-L., Lai, C.-Y. (2010) Motivations of Wikipedia Content Contributors. Computers in Human Behavior, 26 (6), pp. 1377-1383; Parasarnphanich, P., Wagner, C. (2011) Explaining the Sustainability of Digital Ecosystems based on the Wiki Model Through Critical-Mass Theory. IEEE Transactions on Industrial Electronics, 58 (6); and others.

58 For more information on self-determination theory and intrinsic and extrinsic motivations see Ryan, R. M., Deci, E. L. (2000) Intrinsic and Extrinsic Motivations: Classic Definitions and New Directions. Contemporary Educational Psychology, 25 (1), pp. 54-67; Deci, E. L., Ryan, R. M. (1985) Intrinsic Motivation and Self-Determination in Human Behaviour, New York: Springer.

59 Oreg, S., Nov, O. (2008) Exploring motivations for contributing to open source initiatives: The roles of contribution context and personal values. Computers in Human Behavior, 24 (5); Ye, Y., Kishida, K. (2003) Toward an Understanding of the Motivation of Open Source Software developers. ICSE '03 Proceedings of the $25^{\text {th }}$ International Conference on Software Engineering. 
work. The predominance of intrinsic rather than extrinsic motivations, on the other hand, still draws focus to value for autonomy and appreciation for personal beliefs, choices and decisions. There certainly is a connection between Wikipedians and "authors" as portrayed through the EU originality standard, just that the emphasis is not on creativity, but other values like enjoyment or openness.

On the other hand, Wikipedia community rules that define acceptable content and that which has no chance of passing the communal peer-review complement the picture of Wikipedian's relationship with her work. The "Five Pillars" 60 and the "Rules of writing articles" ${ }^{61}$ contain the following requirements for content:

- Neutral point of view (meaning that articles have to be objective and present a wide array of different opinions of others).

- Verifiability (meaning that all statements have to be backed by reliable sources, especially the controversial ones).

- No original research (which requires authors to present the existing knowledge without adding any new and unsupported theories or analyses).

In essence, all these principles are not much different from the standards that would be applicable to any other encyclopaedia. The Encyclopaedia Britannica describes similar features of encyclopaedias as a whole, including the fact that most of them are compilation works created by many contributors working together. ${ }^{62}$ Something that sets Wikipedia apart is, however, its special need for verifiability, namely, external references, which create trust not only among the contributors but also between the reader and the authors. ${ }^{63}$ In addition, there are opinions that the "Neutral point of view" principle is stronger in Wikipedia than in the traditional encyclopaedias ${ }^{64}$, most likely for the same reason of trust between readers and authors which is more easy to establish in the case

${ }^{60}$ (2017) Wikipedia: Five Pillars. [online] Available from: https://en.wikipedia.org/wiki/ Wikipedia:Five_pillars [Accessed 10 February 2017].

${ }_{61}$ (2017) Help: Introduction to Policies and Guidelines/2. [online] Available from: https://en.wikipedia.org/wiki/Help:Introduction_to_policies_and_guidelines/2 [Accessed 10 February 2017].

${ }^{62}$ Preece, W. E. and Collison, E. L. (2016) Encyclopaedia: Reference Work [online] Available from: https://global.britannica.com/topic/encyclopaedia [Accessed 10 February 2017].

${ }_{63}$ See Sundin, O. (2010) Janitors of Knowledge: constructing knowledge in the everyday life of Wikipedia editors. Journal of Documentation, 67 (5), for detailed analysis on how referencing "stabilises knowledge" on Wikipedia. 
of printed encyclopaedia: traditional encyclopaedias are usually more readily accepted for a source of impartial knowledge. Taken together with restrictions of creative choices present in the genre of encyclopaedia as such, it can be concluded that no, or very little, creative effort, freedom of choice or similar continental originality standards are involved when creating Wikipedia. In the same vein, something like "personal touch" is neither expected nor really desirable in Wikipedia at all. What seems to be the most important in the "Five Pillars" and other rules is the final product, its neutrality and usability, not the creative process of the author.

Looking at the formal requirements of Wikipedia and dismissing the motivations of creators, the traditional common law "skills and effort criterion" is closer to the requirements for content in Wikipedia. The work of neutrally compiling well-referenced representation of human knowledge is rather technical and non-creative, but requiring investment of time, skill and judgement. ${ }^{65}$ Nevertheless, the discussion about motivations of Wikipedians clearly show that this result can be achieved in different ways and that rules and requirements in Wikipedia are flexible enough or even perhaps especially fitting to accommodate them. In other words, opposite from the EU copyright law that values process and individual autonomy over the result (there may or may not be "personal touch" imprinted on the final product), Wikipedia community has clear requirements on the result, but very little to say about the choices to be made. At the same time, even the result valued by Wikipedia community is very different from the result of creative choices envisioned in the EU copyright law. It is functional, useful and personality-neutral. After all, Wikipedia is a process, not really a finalised work. It is always in a state of a work-in-progress most articles being constantly edited and rewritten in certain predictable patterns. ${ }^{66}$ Therefore such notions as "personal touch"

64 Bruns, A. (2006) Blogs, Wikipedia, Second Life and Beyond. From Production to Produsage, New York: Peter Lang, p. 113.

65 The same can be observed in the process of becoming an administrator, for instance - most likely these are people who have put a lot of investment of skill and effort and are well known for their contributions. See (2017) Wikipedia: Guide to requests for adminship. [online] Available from: https:/en.wikipedia.org/wiki/Wikipedia:Guide_to_requests_for_adminship [Accessed 10 February 2017]. This can also be said about perhaps the only formal reward in Wikipedia - a barnstar, which are awarded for "hard work and due diligence" (2017) Wikipedia: Barnstars. [online] Available from: https://en.wikipedia.org/wiki/Wikipedia: Barnstars [Accessed 10 February 2017].

66 (2017) Wikipedia: Authors of Wikipedia [online] Available from: https://en.wikipedia.org/wiki/ Wikipedia:Authors_of_Wikipedia [Accessed 10 February 2017], also, Cardon, D. (2012) Discipline but not Punish: The governance of Wikipedia. In: Massit-Follea, F., Meadel, C., Monnoyer-Smith, L. (eds.) Normative Experience in Internet Politics. Paris: Presses Des Mines. 
are abstract in this context - whose personal touch and at what point of time should we be looking for? ${ }^{67}$

\subsection{WIKIPEDIAN'S RELATIONSHIP WITH OTHERS}

From the analysis of the EU originality it could be deduced, that the relationship of the author with society is mostly about the author, not that much about society. The previous section demonstrated, that Wikipedia community, on the opposite, values utility and openness of knowledge above the freedom of choices for the creator. This is, in addition, confirmed by the CC-BY-SA Creative Commons license Wikipedia is using ${ }^{68}$ and by their commitment to creation of "free encyclopedia"69 accessible to everyone. Moreover, the Wikipedian Creative Commons license also comes with "share-alike" condition, which requires any new work incorporating materials from Wikipedia to be licensed under exactly the same CC-BY-SA license. Of course, to a great extent this provision helps to protect the free content from enclosure, but it also gives an edge to the seeming altruism and devotion of the Wikipedia community to the general public. Clearly, the mission of Wikipedia is not only to give, it is also to actively spread a certain ideological attitude towards knowledge as such and make sure that the giving is in some way reciprocated. This is one of the few rights that the authors of Wikipedia hold after signing the initial copyright protection away. ${ }^{70}$

However, even more detailed picture of the Wikipedia emerges when one more aspect of the relationship with others - the relationship within the community is investigated. This aspect of the "relationship with others" is not even discussed in the EU originality analysis above as in this context the relationship with a certain creative community (or a group of other authors in the case of joint authorship) could be only important to assess

\footnotetext{
67 Also see van Gompel, S. (2014) Creativity, autonomy and personal touch. A critical appraisal of the CJEU's originality test for copyright. In: van Eechoud, M. (ed.) The Work of Authorship. Amsterdam: Amsterdam University Press, elaborating on this point.

68 Creative Commons: Attribution-ShareAlike 3.0 Unported (CC BY-SA 3.0). [online] Available from: https://creativecommons.org/licenses/by-sa/3.0/deed.en [Accessed 10 February 2017].

69 The official Wikipedia slogan is "The free encyklopedia that anyone can edit", see (2017) Wikipedia [online] Available from: https://en.wikipedia.org/wiki/Wikipedia [Accessed 10 February 2017].

70 The right to demand from others to keep their works free is not part of the original bundle of copyright. It is a right that can be said to have been "invented" by the Open Access movement and realised through different open licenses.
} 
if there was no significant obstruction to the freedom of creative choices ${ }^{71}$. In Wikipedia, this type of relationship is much more important.

The same Creative Commons license is also the key to "anyone can edit" principle in Wikipedia ${ }^{72}$ and is the legal basis for the internal relationships in the community. Only through editing someone else's work one can become a Wikipedian and it's this condition which makes any piece of text in Wikipedia an object of a rigorous peer-review by anyone who is interested. The license is, however, only the first step - there is an impressive amount of additional communal norms dealing with internal relations. Even though there are different opinions ${ }^{73}$, the prevalent view is that normative structure of Wikipedia is a relatively stable and very complex system that has a number of common features with any traditional bureaucracy. ${ }^{74}$ However, the most important here is that among the different rules, policies, guidelines, manuals and other internal normative material in Wikipedia site the joining "red thread" is collaboration. ${ }^{75}$ Collaboration is the key feature even of the normative structure itself, as one of the main rules, or rather, ideological principles of Wikipedia is that there are no rules ${ }^{76}$ and most questions are solved seeking consensus from everyone involved. Moreover, this is not an aim in itself - this is likely the most effective way to combine the creation of a reliable end product and make community functional in the long term (especially having in mind that all the contributions are made on a voluntary basis).

In fact, collaboration in Wikipedia is as important, and sometimes even more important, than the rules on quality of the content. J. M. Reagle in his

An example could be a case where the tasks for the author were very limited or defined strictly so that only insufficient freedom of choice would be possible.

72 (2017) Wikipedia: Who writes Wikipedia?. [online] Available from: https://en.wikipedia.org/ wiki/Wikipedia:Who_writes_Wikipedia\%3F [Accessed 10 February 2017].

73 D. Wielsch, for instance, calls all the norms in Wikipedia nothing more than User Generated Content as well, which is constantly edited and remade. In Wielsch, D. (2010) Governance of Massive Multiauthor Collaboration. Linux, Wikipedia, and Other Networks: Governed by Bilateral Contracts, Partnerships, or Something in Between? JIPITEC, 1 (2).

74 Joyce, E., Pike, J. C., Butler, B. S. (2012) Rules and Roles vs. Consensus: Self-Governed Deliberative Mass Collaboration Bureaucracies. American Behavioral Scientist, 57 (5); and Heaberlin, B., DeDeo, S. (2015) The Evolution of Wikipedia's Norm Network. Future Internet, 8 (2).

75 Heaberlin, B., DeDeo, S. (2015) The Evolution of Wikipedia's Norm Network. Future Internet, 8 (2).

76 The number 5 of the "five pillars" (2017) Wikipedia: Five Pillars. [online] Available from: https://en.wikipedia.org/wiki/Wikipedia:Five_pillars [Accessed 10 February 2017]. 
comprehensive review of Wikipedia's collaboration phenomenon ${ }^{77}$ identifies two key features making the collaboration possible: the "Neutral Point of View" principle ${ }^{78}$ and the good faith requirement (and presumption) ${ }^{79}$. The Neutral Point of View is a principle stipulating equal respect to all points of view on a specific topic, not merely equal coverage of different views and sources, and as such dictates certain epistemic perspective to be taken by a Wikipedian. ${ }^{80}$ The Good Faith principle asks to see the humanity of the other and to always assume that edits, mistakes, and all statements are made in a good faith. Dealing with the same questions of collaboration, D. Cardon gives specific emphasis to the rule of "No Personal Attacks" which is one of the key rules when it comes to dispute resolution. "No personal Attacks" essentially means that any comments must be made only in relation to content, not the contributor, which allows to foster good faith and collaborative atmosphere with least risk of someone being insulted. ${ }^{81}$ In a system like that, the outcome of a dispute is oriented towards consensus and compromise, not the "absolute $t^{r u t h "}{ }^{82}$, all views and all contributors have to be respected. Consequently, in Wikipedia, sanctions are few and formal dispute resolution seldom needed. ${ }^{83}$

77 Reagle, J. M. J. (2010). Good Faith Collaboration. The Culture of Wikipedia, Cambridge: MIT Press.

78 (2017) Wikipedia: Neutral Point of View. [online] Available from: https://en.wikipedia.org/ wiki/Wikipedia:Neutral_point_of_view [Accessed 10 February 2017].

${ }^{79}$ (2017) Wikipedia: Assume Good Faith. [online] Available from: https://en.wikipedia.org/ wiki/Wikipedia:Assume_good_faith [Accessed 10 February 2017]. This principle is, indeed, often referenced in discussions in Wikipedia and is a key in most of its dispute resolution recommendations and procedures: (2017) Wikipedia: Assume the Assumption of Good Faith. [online] Available from: https://en.wikipedia.org/wiki/Wikipedia:Assume_the_assumption_ of_good_faith [Accessed 10 February 2017].

80 Reagle, J. M. J. (2010) Good Faith Collaboration. The Culture of Wikipedia. Cambridge: MIT Press, pp. 53-59.

${ }^{81}$ Cardon, D. (2012) Discipline but not Punish: The governance of Wikipedia. In: Massit-Follea, F., Meadel, C., Monnoyer-Smith, L. (eds.) Normative Experience in Internet Politics. Paris: Presses Des Mines.

82 "Wikipedia is not about winning" - state the guidelines on dispute resolution: (2017) Wikipedia: Dispute Resolution. [online] Available from: https://en.wikipedia.org/wiki/ Wikipedia:Dispute_resolution [Accessed 10 February 2017], (2017) Wikipedia: Neutral Point of View. [online] Available from: https://en.wikipedia.org/wiki/Wikipedia:Neutral_point_of_ view [Accessed 10 February 2017].

${ }^{83}$ Cardon, D. (2012) Discipline but not Punish: The governance of Wikipedia. In: Massit-Follea, F., Meadel, C., Monnoyer-Smith, L. (eds.) Normative Experience in Internet Politics. Paris: Presses Des Mines. There is a formal Arbitration Committee but only for questions the community was unable to resolve by itself (2017) Wikipedia: Arbitration Committee. [online] Available from: https://en.wikipedia.org/wiki/Wikipedia:Arbitration_Committee [Accessed 10 February 2017]. 
When the internal relationship in the community is almost as important as the quality of the product itself, it can be speculated that the rules of good faith, neutral point of view and no personal attacks are by themselves requirements for the Wikipedian. Quality and compliance with standards are important to usability of the end product and further the agenda of the openness of knowledge, however, without collaboration even the good contributions and smart contributors can be pushed out from Wikipedia.

\subsection{PRESUMPTIONS ABOUT WIKIPEDIAN'S PERSONALITY AND CREATIVE PROCESS}

As was demonstrated, the CJEU dealing with the questions of originality in the EU copyright law makes certain presumptions about the author's creative process and her personality. As also already discussed, in Wikipedia, it is the end product and the community which take the central stage. Still, as in the EU copyright cases explored above, the presumptions about author are more explanations on why the formal normative requirements for the creative output and the creative process are the way they are, not criteria by themselves. Analysing these presumptions helps to understand the other elements and finishes the picture of the author.

First of all, an important question to answer is whose presumptions about the Wikipedia contributors are important? In the analysis of EU originality above, the presumptions by the CJEU were scrutinised, but there is no authoritative body that interprets and makes decisions in Wikipedia it's the community itself. The elements already analysed show a clear difference between Wikipedia and the EU copyright law. In such community as Wikipedia, the romantic notions of isolated creativity and uniqueness of each creator become meaningless. However, the various motivations of Wikipedia contributors and their ideological engagement do show a certain image of the self, typical Wikipedia contributor exhibits, which is in some respects not less romantic. ${ }^{84}$

According to S. Dusollier, for instance, the nature of the creative process in Open Source and copyleft movements is akin to the model proposed

84 Chon, M. (2012) The Romantic Collective Author. Vanderbilt Journal of Entertainment and Technology Law, 14 (4), pp. 829-849. 
by the post-modernists. ${ }^{85}$ The famous post-modern manifesto of the "death of the author" deconstructed the text and the author, proclaimed the text to be "open" and the reader as an equal (or even more important) participant in creation of meaning. ${ }^{86}$ S. Dussolier argues that the collaborative nature and the seemingly unconditional surrender of the Open Source work to the user and an invitation to contribute to the meaning is exactly in the vein of the post-modernist view. Something that can be clearly applicable to the Wikipedia community as visible from the previous sections. Chen Wei Zhu, on the other hand, points out that even in collaborative communities there are definitely still points where the author connects to her work, attribution (which is also the right kept by all Wikipedia contributors through the Creative Commons license) being one of them. ${ }^{87}$ Zhu, following R. Kwall ${ }^{88}$ identifies the Open Source author as a "steward" who acknowledges that his ability to create comes from the outside (the OS community) and who feels the need to give back to the same community afterwards.

Both of these accounts seem to have insights explaining the certain features of Wikipedia community as well. However, the "author is not important at all" approach does not fit the requirements of attribution still present in Wikipedia, nor the strong communal culture and insistence on observation of strict community rules. "Steward" model, on the other hand, does not really explain fun and enjoyment as being predominant motivations for contributing as shown in the section 3.1 above. If both of these models and the observations in the previous sections are combined, though, we see ideology of openness, removal of the "author" away from the central stage and steward-like surrender of the control of text to society and community, but still an individual, a Wikipedian, who is actively choosing this path of creativity, actively participating in a community, and enjoying it in the process. The author in Wikipedia is not dead, she is transformed into something that is perhaps best called

85 Dusollier, S. (2003) Open Source and Copyleft: Authorship Reconsidered. Columbia journal of law \& the Arts, 26 (3).

86 Barthes, R. (1967) The Death of the Author. Aspen, 5 (6); Foucault, M. (1979) What is an Author? Screen, 20 (1), pp. 13-33; etc.

87 Zhu, C. W. (2014) A regime of droit moral detached from software copyright? - the undeath of the 'author' in free and open source software licensing. International Journal of Law and Information Technology, 22 (4).

88 Kwall, R. R. (2010) The Soul of Creativity. Forging Moral Rights Law for the United States. Standford: Standford Law Books. 
a "sharer". According to Oxford English dictionary, sharer means someone who shares something or shares in something ${ }^{89}$ and Wikipedian is exactly that, in both meanings of the word. Moreover, it stipulates that the person wants and has something to share. "Sharer" can easily accommodate the ideology of openness within and outside the community as well as the personal agency of this transformed author: sharing requires someone to do it and does not exclude reciprocity nor respect among all parties involved (as opposed to, for instance, gift giving). Such "revelation" might be borderline banal, as sharing as a phenomenon is the factor characterising the Web 2.0 environment. This simple solution, however, allows going to the heart of the problem: a Wikipedian is a sharing author. How can copyright law accommodate that?

\section{CONCLUSIONS}

The simple answer to this question raised in the last paragraph is, of course, allowing the author to keep only the attributes of copyright that suit her needs and providing conditions for free sharing. The Creative Commons license mentioned above takes care of all that. Going deeper into the structure of copyright law, however, as in this case - into the standard of originality - makes it much harder to provide a clear answer.

As elaborated above, originality in the context of the EU copyright law after the harmonisation by the CJEU is the main criterion for protection of a creative work. This is a criterion that ultimately determines if the creator of the work in question receives the copyright and all the rights related to it, including the right to call oneself an "author". As was demonstrated, the "author" which this standard of originality is directed towards is not really the same as the concept in the Wikipedian context. How, then is originality understood in Wikipedia and how would it compare with the legal standard provided by the CJEU?

Originality in the case of the sharing Wikipedia author, or, so to say, the basis for "protection" or basis for something to stay in Wikipedia, has a lot to do with Wikipedian community and participation in it. It is through the community that the rules on what Wikipedia is and what amounts to good quality are negotiated, established and amended. This is

89 Oxford University Press. (2013) Oxford English Dictionary Online. [online dictionary]. Available from: http://www.oed.com.ludwig.lub.lu.se/viewdictionaryentry/Entry/177541 [Accessed 10 February 2017]. 
the consensus of the community that is important when deciding what is to be deleted and what is to be kept, sometimes even more important than the quality or compliance to other formal guidelines and principles. The community also does not, in general, care what is the motivation of the individual author, nothing is presumed or expected as long as the quality, consensus and ideology of openness are observed. At the same time, neither does community care about what standard of originality copyright law has, the contributions which formally do not need to be "signed away" through a license (like contributions technical in their nature) have no difference in treatment from the ones which are covered by copyright protection. As outlined above, Wikipedia community and its individual members have sharing (including internal collaboration) and openness as the main jointly recognised principles.

If to put all this into the perspective of the originality standard in the EU copyright law, it would then be not "author's own intellectual creation" and "free creative choices" that should be in the focus in Wikipedia. To be accepted to Wikipedia, a work or a contribution has to have a certain kind of "utility" instead. Utility here means not only to the readers and the whole society, but also to the health of the community as a whole. This principle then is able to encompass everything - neutrality, verifiability, ideology of openness, sharing long term sustainability and consensus in the community, etc.

More concretely, if copyright law would aspire to meet the needs of such intrinsically motivated, self-organising sharing communities like Wikipedia, originality standard as the basis of protection should look much more like the common law standard where skill, effort and the value of the final product are emphasized. The path of following the continental copyright and putting author and her creative process in the centre seems to be moving away from the authors of Wikipedia and presumably other similar creators working in such online sharing communities.

On the other hand, the real meaning and the extent of this "utility" Wikipedia is basing authors' participation on, needs to be explored further. The project of Wikipedia - the community as well as the result of its work is always changing and is never finalised. Technology, community and the final product are integrated to form an almost inseparable whole: it is the openness of the technology and the aspiration for encyclopaedia that makes the community necessary and, at the same time, possible. The mere 
fact that some contributions are irrelevant, outright wrong, obscene or large portions of text are routinely deleted ${ }^{90}$ (in other words, the absolute openness of the text) makes it necessary for contributors to organise, constantly track the changes others make and simply return to Wikipedia repeatedly to make sure their contribution is not unduly replaced or distorted. The reality that anyone can add their view makes it necessary for all views to be represented neutrally. The sheer practicality of achieving cooperation of at least those who are driven by similar ideology and goals makes the community structure necessary. One could go on and on like this pointing out the connections between the different layers in Wikipedia, but the most important here is that in this context contributions of any kind are valuable. Moreover, all of them are recorded and stay in the history of the page forever. Without the malicious contributions Wikipedia would not be the same. ${ }^{91}$ More importantly, all contributions will be rewritten or changed or deleted some day, many of the edits made in 2006 are now only present as a historical record in the history section of a relevant Wikipedia page. In such environment what is useful? Or rather, what is not?

Clearly, a limit needs to be drawn, as not all of these activities are even called "contributions", nor are their originators called Wikipedians. However, this could also indicate that originality might, differently from the EU copyright law, not be the main and only criterion for calling someone an "author". On the other hand, even if a limit based on the level of utility would be drawn, it could mean that the recognition of the input of the broader community, i.e. even those whose contributions do not give significant utility to the community or society, might still be an important aspect of Wikipedian community. ${ }^{92}$ Further studies on this would not only give more insights on how the EU copyright law could better accommodate the needs of sharing online communities like Wikipedia, but also might

90 The extent and reoccurrence of these events is well revealed and illustrated in Viegas, F. B., Wattenberg, M., Dave, K. (2004) Studying Cooperation and Conflict between Authors with history flow Visualisations. CHI '04 Proceedings of the SIGCHI Conference on Human Factors in Computing Systems, pp. 575-582.

91 This, in fact, can be well illustrated also by the split views community continues to have about possible introduction of obscenity filters in Wikipedia Laat, P. B. (2012) Coercion or empowerment? Moderation of content in Wikipedia as 'essentially contested' bureaucratic rules. Ethics and Information Technology, 14 (2), pp. 123-135.

92 Evidenced, for instance, by the fact that all of the contributions stay in the Wikipedia site's $\log$. 
help to give guidance into how the EU copyright law could be more sensitive to community or social context always surrounding any author. ${ }^{93}$

\section{LIST OF REFERENCES}

[1] (2017) Help: Introduction to Policies and Guidelines/2. [online] Available from: https://en.wikipedia.org/wiki/Help:Introduction_to_policies_and_guidelines/2 [Accessed 10 February 2017].

[2] (2017) Help: Minor edit. [online] Available from: https://en.wikipedia.org/wiki/Help: Minor_edit [Accessed 10 February 2017].

[3] (2017) Wikipedia [online] Available from: https://en.wikipedia.org/wiki/Wikipedia [Accessed 10 February 2017].

[4] (2017) Wikipedia: About. [online] Available from: https://en.wikipedia.org/wiki/ Wikipedia:About [Accessed 10 February 2017].

[5] (2017) Wikipedia: Arbitration Committee. [online] Available from: https://en.wikipedia. org/wiki/Wikipedia:Arbitration_Committee [Accessed 10 February 2017].

[6] (2017) Wikipedia: Assume Good Faith. [online] Available from: https://en.wikipedia.org/ wiki/Wikipedia:Assume_good_faith [Accessed 10 February 2017].

[7] (2017) Wikipedia: Assume the Assumption of Good Faith. [online] Available from: https://en.wikipedia.org/wiki/Wikipedia:Assume_the_assumption_of_good_faith [Accessed 10 February 2017].

[8] (2017) Wikipedia: Authors of Wikipedia. [online] Available from: https://en.wikipedia.org/ wiki/Wikipedia:Authors_of_Wikipedia [Accessed 10 February 2017].

[9] (2017) Wikipedia: Barnstars. [online] Available from: https://en.wikipedia.org/wiki/ Wikipedia:Barnstars [Accessed 10 February 2017].

[10] (2017) Wikipedia: Copyrights. [online] Available from: https://en.wikipedia.org/wiki/ Wikipedia:Copyrights [Accessed 10 February 2017].

[11] (2017) Wikipedia: Dispute Resolution. [online] Available from: https://en.wikipedia.org/ wiki/Wikipedia:Dispute_resolution [Accessed 10 February 2017].

[12] (2017) Wikipedia: Five Pillars. [online] Available from: https://en.wikipedia.org/wiki/ Wikipedia:Five_pillars [Accessed 10 February 2017].

93 See, for instance, Zemer, L. (2007) The Idea of Authorship in copyright, Adershot: Ashgate. For a discussion about copyright's lack of sensitivity to author's relationship with surrounding social fabrics during her creative process. 
[13] (2017) Wikipedia: Guide to requests for adminship. [online] Available from: https://en.wikipedia.org/wiki/Wikipedia:Guide_to_requests_for_adminship [Accessed 10 February 2017].

[14] (2017) Wikipedia: Neutral Point of View. [online] Available from: https://en.wikipedia. org/wiki/Wikipedia:Neutral_point_of_view [Accessed 10 February 2017].

[15] (2017) Wikipedia: Reusing Wikipedia Content. [online] Available from: https://en. wikipedia.org/wiki/Wikipedia:Reusing_Wikipedia_content

[Accessed 10February 2017].

[16] (2017) Wikipedia: Statistics. [online] Available from: https://en.wikipedia.org/wiki/ Wikipedia:Statistics [Accessed 10 February 2017].

[16] (2017) Wikipedia: Wikipedians. [online] Available from: https://en.wikipedia.org/wiki/ Wikipedia:Wikipedians [Accessed 10 February 2017].

[17] (2017) Wikipedia: Who writes Wikipedia?. [online] Available from: https://en.wikipedia. org/wiki/Wikipedia:Who_writes_Wikipedia\%3F [Accessed 10 February 2017].

[18] Barthes, R. (1967) The Death of the Author. Aspen, 5-6.

[19] Bezpečnostní softwarová asociace - Svaz softwarové ochrany v. Ministerstvo kultury. (2010) Case no. C-393/09. Court of Justice of the European Union, ECR I-13971.

[20] Bruns, A. (2006) Blogs, Wikipedia, Second Life and Beyond. From Production to Produsage, New York: Peter Lang.

[21] Cardon, D. (2012) Discipline but not Punish: The governance of Wikipedia. In: Massit-Follea, F., Meadel, C., Monnoyer-Smith, L. (eds.) Normative Experience in Internet Politics. Paris: Presses Des Mines.

[22] Chon, M. (2012) The Romantic Collective Author. Vanderbilt Journal of Entertainment and Technology Law, 14 (4).

[23] Creative Commons: Attribution-ShareAlike 3.0 Unported (CC BY-SA 3.0). [online] Available from: http://creativecommons.org/licenses/by-sa/3.0/deed.en

[Accessed 10 February 2017].

[24] Deci, E. L., Ryan, R. M. (1985) Intrinsic Motivation and Self-Determination in Human Behaviour, New York: Springer.

[25] Directive 2001/29/EC of the European Parliament and of the Council of 22 May 2001 on the Harmonisation of Certain Aspects of Copyright and Related Rights in the Information Society, Official Journal of European Union (L 167/10) 22 June.

[26] Dusollier, S. (2003) Open Source and Copyleft: Authorship Reconsidered. Columbia Journal of Law \& the Arts, 26 (3). 
[27] Erickson, K. (2014) User illusion: ideological construction of 'user-generated content' in the EC consultation on copyright. Internet Policy Review, 3 (4).

[28] Eva Maria Painer v. Standard Verlags GmbH and others. (2011) [unreported] Case no. C-145/10. Court of Justice of the European Union, 7 March.

[29] Foucault, M. (1979) What is an Author? Screen, 20 (1).

[30] Football Association Premier League Ltd, NetMed Hellas SA, Multichoice Hellas SA v. QC Leisure, David Richardson, AV Station plc, Malcolm Chamberlain, Michael Madden, SR Leisure Ltd, Philip George Charles Houghton, Derek Owen, and Karen Murphy v. Media Protection Services Ltd. (2011) Joined cases nos. C-403/08 and C-429/08. Court of Justice of the European Union, ECR I-10909.

[31] Football Dataco Ltd, Football Association Premier League Ltd, Football League Ltd, Scottish Premier League Ltd, Scottish Football League, PA Sport UK Ltd v. Yahoo! UK Ltd, Stan James (Abingdon) Ltd, Stan James plc, Enetpulse ApS. (2012) [unreported] Case no. C-604/10. Court of Justice of the European Union, 1 March.

[32] Heaberlin, B., DeDeo, S. (2015) The Evolution of Wikipedia's Norm Network. Future Internet, 8 (2).

[33] Halatchliyski, I., Moskaliuk, J., Joachim, K., Cress, U. (2014) Explaining authors' contribution to pivotal artefacts during mass collaboration in the Wikipedia's knowledge base. Computer Supported Cooperative Learning, 9 (1).

[34] Halbert, D. (2014) The State of Copyright: the Complex Relationships of Cultural Creation in a Globalised World, New York: Routledge.

[35] Infopaq International A/S v. Danske Dagblades Forening (2009) Case no. C-5/08. Court of Justice of the European Union, ECR I-06569.

[36] Jaszi, P. (1994) On the Author effect: Contemporary Copyright and Collective Creativity. In: Woodmansee, M., Jaszi, P. (eds.) The Construction of Authorship. Textual Appropriation in Law and Literature. Durham: Duke University Press.

[37] Joyce, E., Pike, J. C., Butler, B. S. (2012) Rules and Roles vs. Consensus: Self-Governed Deliberative Mass Collaboration Bureaucracies. American Behavioral Scientist, 57 (5).

[38] Kawashima, N. (2010) The rise of 'user creativity' - Web 2.0 and a new challenge for copyright law and cultural policy. International Journal of Cultural Policy, 16 (3).

[39] Kwall, R. R. (2010) The Soul of Creativity. Forging Moral Rights Law for the United States. Standford: Standford Law Books.

[40] Laat, P. B. (2012) Coercion or empowerment? Moderation of content in Wikipedia as 'essentially contested' bureaucratic rules. Ethics and Information Technology, 14 (2). 
[41] Lai, C.-Y., Yang, H.-L. (2014) The reasons why people continue editing Wikipedia content - task value confirmation perspective. Behaviour E Information Technology, 33 (12).

[42] Lavik, E. (2014) Romantic authorship in copyright law and the uses of esthetics. In: van Eechoud, M. (ed.) The Work of Authorship. Amsterdam: Amsterdam University Press.

[43] Lavik, E., van Gompel, S. (2013) On the Prospects of Raising the Originality Requirement in Copyright Law: Perspectives from the Humanities. Journal, Copyright Society of the U.S.A., 60 (3).

[44] Nov, O. (2007) What Motivates Wikipedians. Communications of the ACM, 50 (11).

[45] Oreg, S., Nov, O. (2008) Exploring motivations for contributing to open source initiatives: The roles of contribution context and personal values. Computers in Human Behavior, 24 (5).

[46] Parasarnphanich, P., Wagner, C. (2011) Explaining the Sustainability of Digital Ecosystems based on the Wiki Model Through Critical-Mass Theory. IEEE Transactions on Industrial Electronics, 58 (6).

[47] Peifer, K.-N. (2014) “Individualität" or Originality? Core concepts in German copyright law. GRUR Int., 63 (12).

[48] Pentzold, C. (2010) Imagining the Wikipedia community: What do Wikipedia authors mean when they write about their 'community'. New Media \& Society, 13 (5).

[49] Phillips, J. (2009) Authorship, ownership, wikiship: copyright in the $21^{\text {st }}$ century. In: Derclaye, E. (ed.) Research Handbook on the Future of EU Copyright. Cheltenham: Edward Elgar.

[50] Preece, W. E. and Collison, E. L. (2016) Encyclopaedia: Reference Work [online] Available from: https://global.britannica.com/topic/encyclopaedia [Accessed 10 February 2017].

[51] Quaedvlieg, A. (2014) The tripod of originality and the concept of work in Dutch and European copyright. GRUR Int., 63 (12).

[52] Reagle, J. M. J. (2010) Good Faith Collaboration. The Culture of Wikipedia. Cambridge: MIT Press.

[53] Rosati, E. (2013) Originality in EU Copyright. Full Harmonization through Case Law, Cheltenham: Edward Elgar.

[54] Ryan, R. M., Deci, E. L. (2000) Intrinsic and Extrinsic Motivations: Classic Definitions and New Directions. Contemporary Educational Psychology, 25 (1). 
[55] Samuelson, P. (2003-2004) Should Economics Play a Role in Copyright Law and Policy? University of Ottawa Law \& Technology Journal, 1 (2).

[56] Sundin, O. (2010) Janitors of Knowledge: constructing knowledge in the everyday life of Wikipedia editors. Journal of Documentation, 67 (5).

[57] Torremans, P. (2007) Legal Issues Pertaining to the restoration and reconstitution of manuscripts, sheet music, paintings and films for marketing purposes. In: Torremans, P. (ed.) Copyright Law. A Handbook for Contemporary Research. Cheltenham: Edward Elgar.

[58] Van Gompel, S. (2014) Creativity, autonomy and personal touch. A critical appraisal of the CJEU's originality test for copyright. In: van Eechoud, M. (ed.) The Work of Authorship. Amsterdam: Amsterdam University Press.

[59] Van Gompel, S., Lavik, E. (2013) Quality, Merit, Aesthetics and Purpose: An Inquiry Into EU Copyright Law's Eschewal of other Criteria than Originality. Revue Internationale du Droit d'Auteur (RIDA), 236.

[60] Viegas, F. B., Wattenberg, M., Dave, K. (2004) Studying Cooperation and Conflict between Authors with history flow Visualisations. CHI '04 Proceedings of the SIGCHI Conference on Human Factors in Computing Systems, pp. 575-582.

[61] Wielsch, D. (2010) Governance of Massive Multiauthor Collaboration. Linux, Wikipedia, and Other Networks: Governed by Bilateral Contracts, Partnerships, or Something in Between? JIPITEC, 1 (2).

[62] Xu, B., Li, D. (2015) An empirical study of the motivations for content contribution and community participation in Wikipedia. Information $\mathcal{E}$ Management, 52 (3).

[63] Yang, H.-L., Lai, C.-Y. (2010) Motivations of Wikipedia Content Contributors. Computers in Human Behavior, 26 (6).

[64] Ye, Y., Kishida, K. (2003) Toward an Understanding of the Motivation of Open Source Software developers. ICSE '03 Proceedings of the $25^{\text {th }}$ International Conference on Software Engineering, pp. 419-429.

[65] Zemer, L. (2007) The Idea of Authorship in copyright. Adershot: Ashgate.

[66] Zhu, C.W. (2014) A regime of droit moral detached from software copyright? the undeath of the 'author' in free and open source software licensing. International Journal of Law and Information Technology, 22 (4). 